\title{
Pelatihan Penyusunan Renstra Rumah Sakit: Trend Watching Analysis
}

\author{
Firman Pribadi1, Merita Arini² \\ 1. Magister Manajemen, Program Pascasarjana, Universitas Muhammadiyah Yogyakara, Yogyakarta, Indonesia \\ Email: firmanpribadi@umy.ac.id \\ DOI: $10.18196 / \mathrm{ppm} \cdot 36.308$
}

\begin{abstract}
Abstrak
Rencana strategis (renstra) adalah bagian vital dalam manajemen rumah sakit. Penyusunan renstra saat ini bukanlah hal mudah sehinggs banyak rumah sakit yang menyusunkan renstranya melalui konsultan manajemen dan berbiaya tinggi mulai dari puluhan juta hingga ratusan juta rupiah, tergantung pada tingkat kesulitan dan kedalaman renstra yang dibuat.Tujuan dari pengabdian masyarakat ini adalah melatih staf dan pimpinan rumah sakit yang terlibat dalam penyusunan renstra untuk belajar cara mengumpulkan data, mengolah data, dan menyimpulkan data eksternal dan internal guna melakukan trend watching analysis. Metode pelatihan dilaksanakan secara online melalui media zoom, sedangkan metode trend watching analisis dilaksanakan dengan menggunakan metode proses analisis lingkungan, analisis persaingan industri, dan five forces Michael Porter. Hasil pelatihan menunjukan bahwa peserta pelatihan merasa puas karena mendapatkan pencerahan dan pemahaman yang baik dan komprehensif tentang cara mengolah data dan menyimpulkan hasil pengolahan data lingkungan ekternal dan internal dalam trend watching analysis. Implikasi dari pelatihan ini diharapkan rumah sakit dapat menyusun renstra sendiri terutama terkait trend watching analysis. Setelah pelatihan dilakukan, terdapat peningkatan skill peserta dalam melakukan trend watching analysis sehingga penyusunan renstra sesuai yang dengan persyaratan akreditasi rumah sakit dapat dilakukan.
\end{abstract}

Kata Kunci: renstra, analisis lingkungan eksternal dan internal, trend watching analysis

\section{Pendahuluan}

Semakin banyaknya pendirian rumah sakit baru terutama rumah sakit yang didirikan oleh pihak swasta menjadikan persaingan rumah sakit menjadi semakin agresif dan ketat. Oleh karena itu, manajemen rumah sakit dituntut untuk memahami strategi dan mengimplementasikanya agar bisa memenangkan persaingan. Pemahaman strategi bertujuan tidak hanya untuk bertahan hidup, tetapi juga mampu bertumbuh dengan baik untuk memenangkan persaingan. Salah satu bentuk implementasi strategi adalah dengan menyusun rencana strategis.

Dalam menyusun rencana strategis tahap pertama adalah memahami lingkungan bisnis rumah sakit, baik lingkungan eksternal maupun lingkungan internal rumah sakit atau dikenal dengan trend watching analysis. Pemahaman mengenai kondisi lingkungan terutama dengan mengamati tren perubahan lingkungan, baik eksternal maupun internal, menjadi sangat penting.

Pentingnya analisis lingkungan rumah sakit dijabarkan dalam contoh berikut yang menjelaskan perubahan lingkungan yang sangat dinamis, bahkan dapat mengancam kondisi rumah sakit pernah terjadi belum lama ini. Kondisi yang mengancam ini timbul karena adanya perubahan regulasi pada Peraturan Menteri Kesehatan Nomor 30 Tahun 2019 tentang Klasifikasi dan Perizinan Rumah Sakit sebagai pengganti Peraturan Menteri Kesehatan Nomor 56 Tahun 2014 tentang Klasifikasi dan Perizinan Rumah Sakit. Perubahan regulasi ini sempat membuat rumah sakit kelabakan karena jika benar-benar diterapkan, banyak rumah sakit yang ditengarai akan mengalami kesulitan terutama terkait masalah ketentuan pemenuhan tenaga dokter spesialis tetap rumah sakit. Namun, sebelum Peraturan Menteri Nomor 30 Tahun 2019 ini diterapkan, pada tahun 2020, peraturan ini dibekukan oleh Menteri Kesehatan yang baru terpilih yang menggantikan menteri kesehatan dari kabinet sebelumnya.

Setelah pembekuan Peraturan Menteri Kesehatan Nomor 30 Tahun 2019, pada tahun 2020, keluarlah Peraturan Menteri Kesehatan Nomor 3 Tahun 2020 tentang Klasifikasi dan Perizinan Rumah Sakit sebagai pengganti. Perubahan regulasi yang sangat dinamis ini menunjukkan betapa pentingnya analisis lingkungan bagi rumah sakit karena perubahan yang 
terjadi tidak saja dapat menyulitkan rumah sakit, tetapi dapat juga mengancam keberadaan rumah sakit.

Di sisi lain, perubahan peraturan ataupun lingkungan secara keseluruhan selain ada ancaman di dalamnya juga ada peluang yang bisa dimanfaatkan untuk keuntungan rumah sakit. Seperti keluarnya Peraturan Menteri Kesehatan Nomor 3 Tahun 2020 tentang Klasifikasi dan Perizinan Rumah Sakit telah menghilangkan hambatan-hambatan yang terkait dengan klasifikasi rumah sakit yang ada pada regulasi sebelumnya sehingga perubahan ini dapat dimanfaatkan oleh rumah sakit untuk kemajuan rumah sakit. Pelatihan ini bertujuan mengajarkan kepada pihak rumah sakit cara mengumpukan data, mengolah data, dan menyimpulkan hasil pengolahan data lingkungan eksternal dan internal dalam trend watching analysis guna menyusun renstra rumah sakit.

\section{Metode Pelaksanaan}

Dikarenakan masih dalam masa pandemi Covid-19, pelaksanaan kegiatan dilakukan secara online menggunakan aplikasi zoom yang disediakan pihak rumah sakit mitra. Peserta yang hadir dalam pelatihan ini ada dua belas (12) orang yang terdiri atas staf dan seluruh direksi rumah sakit mitra. Peserta pelatihan mengikuti pelatihan dari ruang serba guna rumah sakit melalui televisi yang disambungkan ke aplikasi zoom. Tim pelatih memberikan pelatihan melalui ruang rapat MARS UMY yang juga menggunakan sambungan televisi dari aplikasi zoom.

Metode analisis lingkungan internal dan eksternal dalam pelatihan ini mengikuti langkah-langkah dari Swayne, Duncan, dan Ginter (2006) sebagai berikut. Pertama, melakukan proses analisis lingkungan yang terdiri atas tahap scanning, monitoring, forecasting, asseing seperti Gambar 1 berikut.

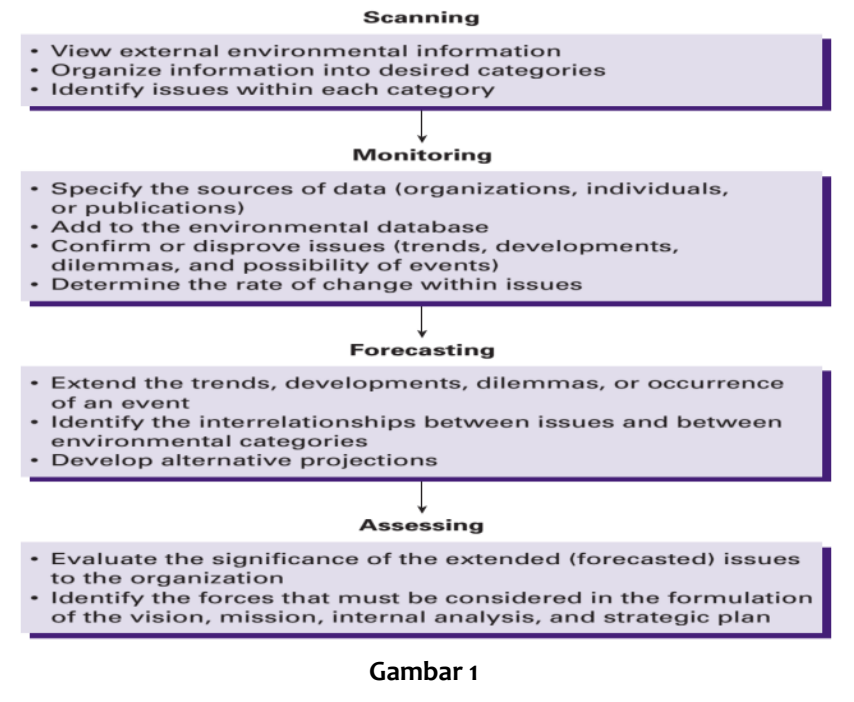

Setelah proses analisis lingkungan selesai dilakukan, langkah selanjutnya adalah melakukan analisis persaingan industri. Langkah-langkah analisis, yaitu menentukan area layanan, analisis pesaing, mengembangkan definisi industri, identifikasi pesaing, dan informasi pesaing seperti Gambar 2 berikut. 


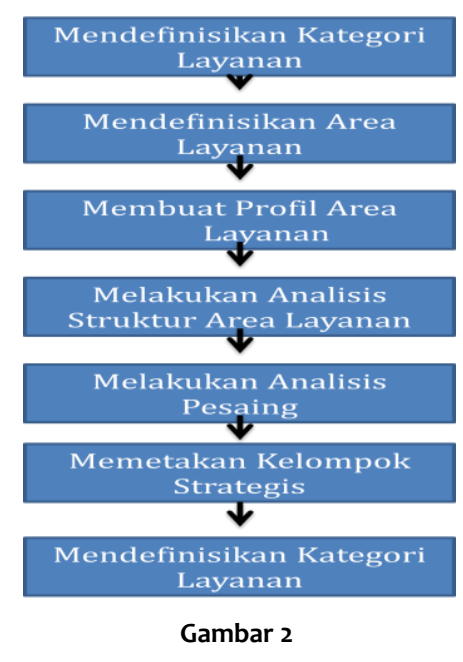

Langkah terakhir melakukan analisis persaingan industri dengan menggunakan five forces dari Michael Porter seperti Gambar 3 berikut.

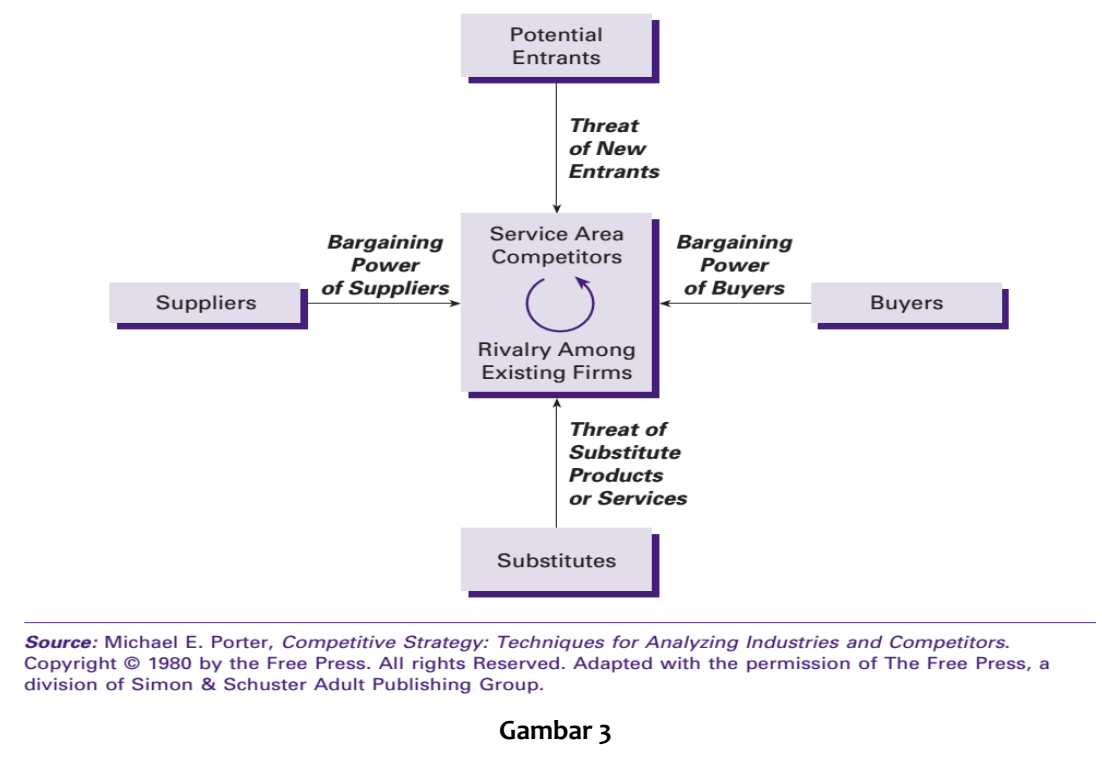

\section{Hasil dan Pembahasan}

Karena rumah sakit RS PKU Muhammadiyah Sruweng belum bisa menyediakan data rumah sakit, pelatihan tetap dilaksanakan menggunakan data dari tim pengabdian masyarakat. Data oleh tim pengabdian masyarakat diambil dari data Working Paper Penyusunan Dokumen Rencana Strategis Bisnis (PMPK UGM, ??) yang tesedia di internet. Diharapkan setelah pelatihan ini, rumah sakit sudah dapat mengumpulkan data dan mengerjakan renstranya baik secara mandiri, maupun tetap dengan bimbingan tim pengabdian. Pelatihan analisis data eksternal dan internal ini selanjutnya dilakukan menggunakan excel. Data yang diolah dalam penelitian ini sebagai berikut.

1. Latihan Analisis Eksternal
a) Tren Pertumbuhan Penduduk
b) Market Share dan Angka Kesakitan
c) Estimasi Jumlah Penduduk Miskin dan Persentasenya terhadap Jumlah Total Penduduk
d) Tren Anggaran Pemerintah Daerah untuk Kesehatan
e) Estimasi Jumlah Peserta BPJS Berdasarkan Data Jumlah ASN 
f) Estimasi Jumlah Penduduk yang Ter-cover Jamkesda

2. Latihan Analisis Lingkungan Internal

a) Tren Kunjungan di Poliklinik

b) Tren Kunjungan di IGD

c) Data Laboratorium untuk Memperoleh Informasi Mengenai Tren, Komposisi Rata-rata dan Informasi Lainnya yang Dibutuhkan untuk Mengembangkan Proyeksi Pasar Laboratorium

d) Data Radiologi untuk Memperoleh Informasi Mengenai Tren, Komposisi Rata-rata dan Informasi Lainnya yang Dibutuhkan untuk Mengembangkan Proyeksi Pasar Radiologi

e) Data kinerja Kamar Operasi untuk Memperoleh Informasi Mengenai Tren, Komposisi Rata-Rata dan Informasi Lainnya yang Dibutuhkan untuk Mengembangkan Proyeksi Pasar Pelayanan Operasi.

f) Data Fisioterapi untuk Memperoleh Informasi Mengenai Tren, Komposisi Rata-rata dan Informasi Lainnya yang Dibutuhkan untuk Mengembangkan Proyeksi Pasar Pelayanan Fisioterapi

Pengolahan data eksternal dimulai dengan menentukan area geografis yang akan menjadi area layanan rumah sakit. Area layanan dibagi menjadi core area (area inti), coverage area (area cakupan), dan noncoverage area (bukan area cakupan). Tujuan pembagian data area geografis ini agar rumah sakit mengetahui data perkiraan pasien yang akan mendatangi rumah sakit. Contoh penduduk yang berada di core area, jika memerlukan layanan gawat darurat, mereka akan segera datang ke rumah sakit terdekat. Penduduk yang berada di coverage area adalah penduduk yang masuk dalam wilayah area pemasaran rumah sakit. Oleh karena itu, penduduk di coverage area akan menjadi terget layanan rumah sakit khusunya bagi layanan nondarurat atau menuju layanan-layanan khusus atau layanan unggulan rumah sakit.

Dalam penentuan area geografis rumah sakit peserta pelatihan menggunakan analisis tren untuk menentukan jumlah penduduk yang berada dalam area geografi. Analisis tren digunakan untuk menentukan perkiraan penambahan jumlah penduduk ke depanya.

Setelah meneyelesaikan data area geografis, peserta mengerjakan data jumlah kunjungan rawat jalan dari seluruh fasilitas kesehatan yang ada, mulai dari puskesmas, dokter praktik, RS pesaing, hingga RS peserta sendiri. Data ini digunakan untuk menentukan angka kesakitan dengan rumus $\frac{\text { JumlahKunjungan Pasin IRJA di seluruhfaskes }}{\text { Jumlah Total Populasi }}$, menentukan tingkat persaingan market share rumah sakit dengan rumus Jumlah Kunjungan Rawat Jalan Rumah Sakit 1 Kunjungan Rawat Jalan di Seluruh Fasilitas Kesehatan. Dari kedua rumus tersebut, kita bisa Jumlah Kunjungan Rawat Jalan di Seluruh Fasilitas Kesehatan.
mengetahui seberapa besar angka kesakitan di suatu wilayah dan berapa besar market share rumah sakit sehingga ke depanya bisa ditentukan strategi yang akan diambil untuk meningkatkan market share rumah sakit peserta.

Langkah selanjutnya adalah menghitung jumlah masyarakat sejahtera, prasejahtera, dan jumlah ASN di suatu daerah. Dengan mengetahui kondisi ekonomi masyarakat di wilayah geografi rumah sakit berada, dapat dilihat siapa pengguna terbesar rumah sakit. Hal ini bermanfaat untuk menentukan strategi kebijakan baik tarif ataupun layanan cost sharing di rumah sakit.

Kemudian pelatihan dilanjutkan dengan menghitung data jumlah dan jenis SDM kesehatan yang ada. Data ini bermanfaat bagi rumah sakit untuk memberikan gambaran ketersediaan tenaga kesehatan di daerah wilayah geografis rumah sakit karena perencanaan pengembangan layanan rumah sakit akan bergantung pada ketersediaan SDM ini. Data SDM juga bermanfaat untuk perbandingan tenaga kesehatan yang ada di rumah sakit peserta dengan rumah sakit sekitarnya. 
Setelah pengolahan data eksternal selesai dilakukan, pelatihan dilanjutkan dengan pengolahan data internal rumah sakit. Pengolahan data internal dimulai dengan menghitung angka kunjungan pasien ke poliklinik yang dibagi menjadi pasien umum, pasien BPJS, dan pasien Jamkesda. Pengolahan data pasien ini untuk melihat perbadingan jenis pasien yang datang ke rumah sakit dan tren jenis pasien yang datang. Data jenis pasien ini akan bermanfaat bagi penyusunan strategi untuk meningkatkan angka kedatangan pasien.

Menghitung kedatangan pasien ke IGD berdasarkan jenis pembayaran pasien, yaitu pasien umum, pasien BPJS, dan Pasien Jamkesda. Kedatangan pasien IGD berdasarkan jenis pembayaran pasien ini juga menggunakan analisis tren. Setelah jumlah kedatangan dan tren pasien ke IGD diketahui langkah selanjutnya adalah membandingkan angka kunjungan ke IGD dengan kunjungan ke poliklinik di atas. Tujuan pembandingan ini untuk mengetahui proporsi pasien yang datang ke IGD. Pelatihan pengolahan data internal dilanjutkan dengan mengolah data Bed Occupancy Rate (BOR), Average Length Of Stay (LOS), Bed Turn Over (BTO), Turn Over Internal (TOI), Gross Death Rate (GDR), Net Death Rate (NDR), dan Jumlah Hari Rawatan untuk melihat kondisi tren. Pengolahan data internal selanjutnya adalah melakukan analisis tren, rata-rata, dan informasi lainya dari Laboratorium, Radiologi, dan Kamar Operasi. Dari analisis tren dan rata-rata ini, rumah sakit memahami bagaimana kinerja dari unit-unit penghasil di rumah sakit.

\section{Simpulan}

Berdasarkan pernyataan dari peserta tampak bahwa semua peserta antusias dalam mengikuti pelatihan karena penyusunan renstra di rumah sakit adalah suatu keharusan yang dikaitkan dengan standar akreditasi rumah sakit (SNARS). Jika diserahkan kepada konsultan manajemen rumah sakit, penyusunan renstra rumah sakit berbiaya mahal mulai dari puluhan juta untuk yang sederhana hingga ratusan juta untuk yang menggunakan riset pasar. Oleh karena itu, pelatihan ini berusaha dimanfaatkan dengan baik oleh pihak RS PKU Muhammadiyah Sruweng.

Hasil pelatihan peserta menyatakan puas atas pelatihan yang diberikan dan tampak adanya peningkatan kemampuan peserta dalam mengolah data, memahami, dan menginterprestasikan data. Selanjutnya, diharapkan bahwa hasil pelatihan ini secara keseluruhan dapat meningkatkan kemampuan peserta dalam menyusun renstra rumah sakit. Antusiasme peserta tampak dari foto-foto berikut.
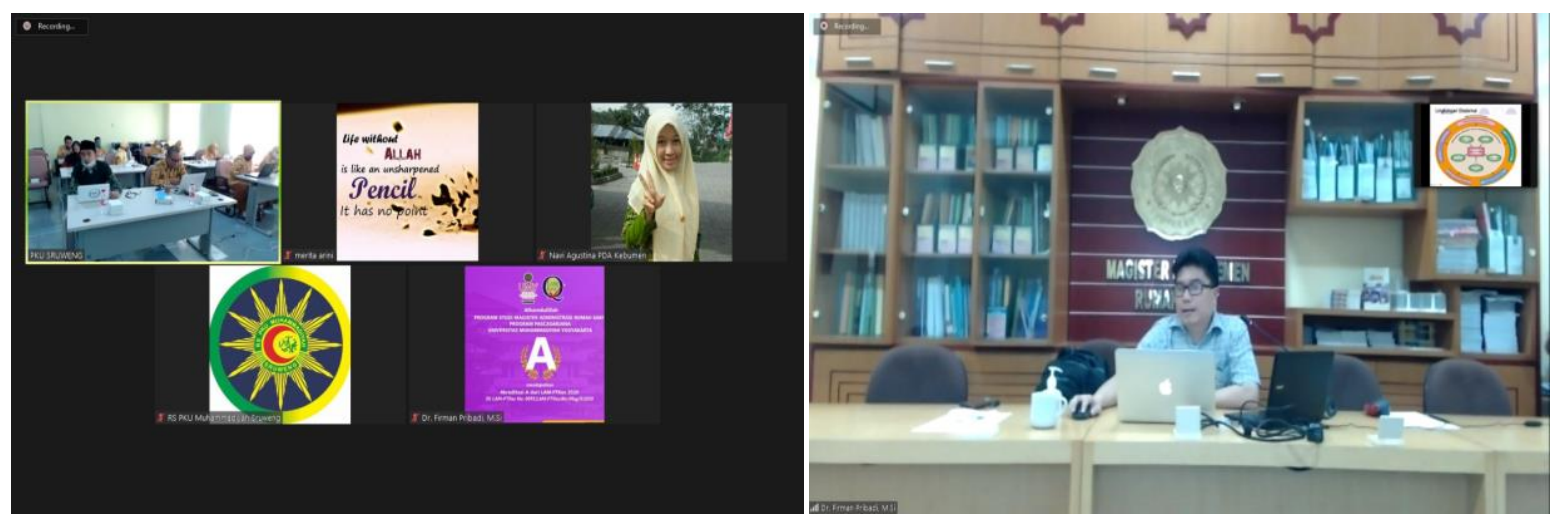


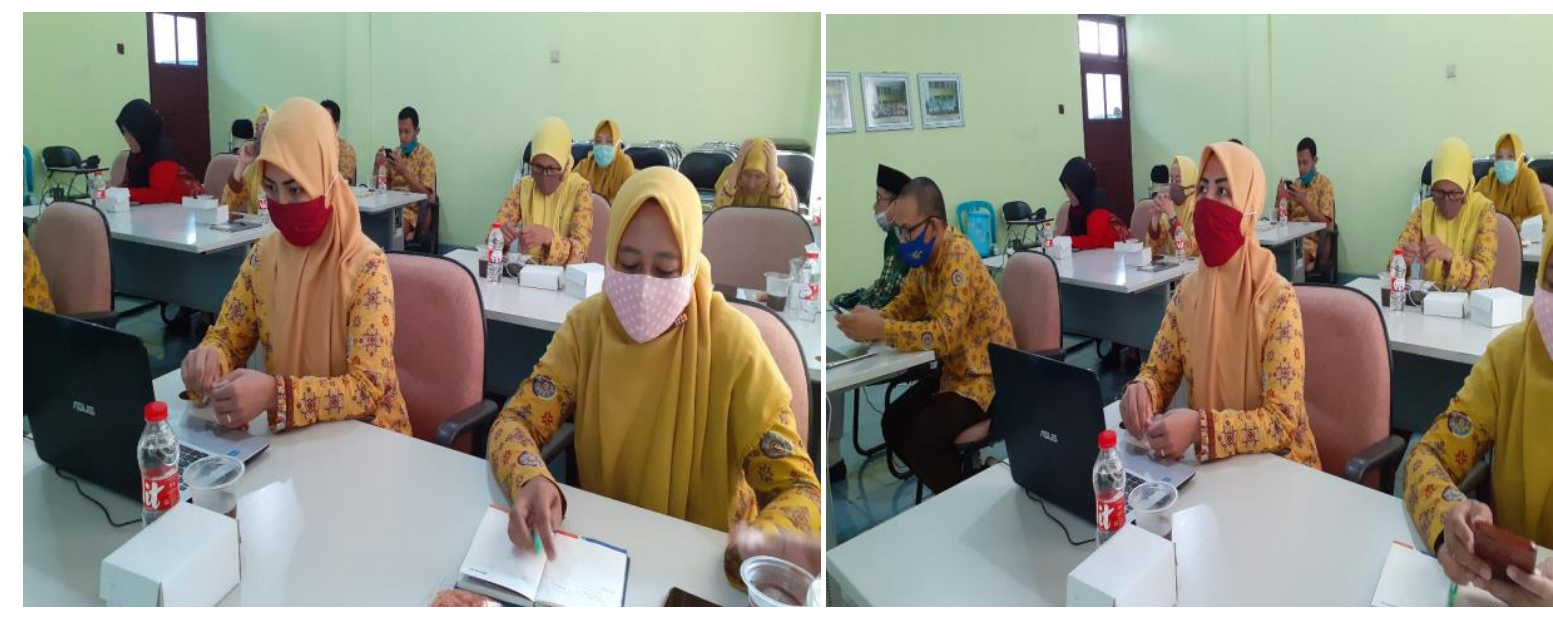

\section{Ucapan Terima Kasih}

Terima kasih penulis ucapkan kepada pihak LP3M PPM UMY yang telah memberikan dana untuk pengabdian masyarakat ini sehingga kegiatan pelatihan dan pandampingan penyusunan renstra dapat terlaksana. Selanjutnya, penulis juga mengucapkan terima kasih kepada rumah sakit mitra, yaitu RS PKU Muhammadiyah Sruweng yang telah bersedia menjadi mitra bagi pelaksanaan pengabdian masyarakat ini.

\section{Daftar Pustaka}

PMPK UGM. (?). Working Paper Penyusunan Dokumen Rencana Strategis Bisnis. Yogyakarta: PMPK UGM.

Swayne, et al. (2006). Strategic Management of Health Care Organization, $5^{\text {th }}$ Edition. UK: Blackwell Publishing. 